\section{Suicide and substance misuse}

JAN NEELEMAN and MICHAEL FARRELL

Most of the secular rise in young male suicide may be related to higher levels of substance misuse among young people (Carlson et al, 1991). Of young suicides in the USA, $53 \%$ qualify for this diagnosis (Fowler $e$ t al, 1986). It is associated with a 15 -fold increased suicide risk (Shaffer $e t$ al, 1996). Suicide accounts for $35 \%$ of deaths of intravenous substance users (Frischer $e t$ al, 1993). Our purpose is to highlight how epidemiological knowledge of the link between substance misuse and suicide has advanced, and to identify pressing areas for research and preventive effort.

\section{BASICISSUES}

Research in this field suffers from the fact that both substance misuse and suicidal behaviour vary widely, from cannabis taking and suicidal ideation, to intravenous use and completed suicide. Studies do not always distinguish between abuse and dependence (Brent et al, 1993; Shaffer et $a l, 1996)$ or between alcohol and other drug misuse (Carlson et al, 1991).

Suicidal behaviour poses problems of measurement and definition which are especially acute when substance misuse is the focus of interest. Suicide by self-poisoning, a method frequently used by addicts (Engström et al, 1991), is under-registered (Neeleman \& Wessely, 1997a). Studies of official suicides only will thus suffer from selection bias. Similar problems apply to non-fatal suicidal behaviour. Opiate addicts who experience non-fatal overdoses are unlikely to seek help (Darke et al, 1996) or be registered as parasuicides, so that they may not be selected into study samples.

\section{CHARACTERISING THE RELATIONSHIPAT THE INDIVIDUAL LEVEL}

Studies which examine substance misuse in suicide victims (psychological autopsies) can be distinguished from those which study suicide in cohorts exposed to substance misuse. Psychological autopsies give risk estimates only if population controls are also examined; few studies, and none from the UK, meet this requirement (Brent et al, 1993; Shaffer et al, 1996). There is agreement that substance misuse is a strong risk factor for suicide among the young but authors disagree about whether it is more (Fowler et al, 1986) or less (Brent et al, 1993) prevalent than depression. Such discussions arise from the absence of controls in many studies. Other unresolved issues concern comorbidity in substance-misusing suicide victims for which estimates range from $44 \%$ (Brent et $a l, 1993$ ) to $100 \%$ (Shaffer et al, 1996), and the timing of symptom onset.

As suicide is rare, prospective studies frequently rely on special cohorts such as parasuicide (Hawton et al, 1993) or psychiatric patients (Allgulander et al, 1992). A salient finding is that substance misuse in parasuicide patients is the best predictor of eventual suicide (Hawton et al, 1993). The suicide rate among intravenous drug users is 30 times that in the general population (Rossow, 1994).

Cross-sectional studies have examined the relationship between substance misuse and non-fatal suicidal behaviour. A strong relation exists between severity of substance misuse (in terms of substance used and route of administration) and risk of non-fatal suicidal behaviour. Both are linked with a history of aggression (Garrison et al, 1993). Substance misuse is associated with a seven times increased risk of attempted suicide (Deykin \& Buka, 1994) but a 15 times increased risk of completed suicide (Shaffer et al, 1996). This suggests that, beyond its link with suicidality per se, substance misuse is associated with higher likelihood of lethal outcome, possibly because more dangerous methods and substances are used by the victim (Neeleman \& Wessely, 1997b).

The impact of substance misuse and dependence on national suicide rates has not yet been quantified (Gunnell \& Frankel, 1994) presumably because the population prevalences are not reliably known. Although many caveats are attached to the use of population attributable fractions, it is interesting that suicide prevention in recently discharged psychiatric patients has been estimated maximally to yield an overall suicide rate reduction of $15 \%$ (Gunnell \& Frankel, 1994). There are few data available to indicate mechanisms by which levels of drug misuse could be reduced in current society but much to indicate that overall levels continue on an upward trend, suggesting an increasing contribution to young suicides over time.

\section{FURTHER RESEARCH AND AVENUES FOR PREVENTION}

Despite accumulating evidence concerning the strength of the link between suicidal behaviour and substance misuse, the underlying mechanisms remain unclear. The link may be attributable to intervening psychiatric disorder such as depression; both depression and substance misuse may result from a third, antecedent condition such as personality disorder, while it is also possible that substance misuse alone may suffice to increase suicide risk particularly associated with impulsive behaviour.

Future studies need to examine how risk factors interact; does the relationship between suicidal behaviour and substance misuse differ by gender, age, levels of comorbidity, type of substance used or sociocultural circumstances?

There is little doubt that suicide prevention should be pursued actively among entrenched drug users. Methadone maintenance helps reduce their suicide risk (Caplehorn et al, 1994). Awareness should be raised of high-risk records, for instance following release from prison, and there needs to be greater awareness of the high levels of undetected depression among drug users (Hall \& Farrell, 1997).

At the milder but more numerous end of the spectrum, prevention of substance misuse in the young is an important target (Department of Health, 1996). Educating the public, primary health care workers and teaching staff about suicide risk associated with substance misuse may need consideration.

Finally, the profile that is emerging of the young person at highest risk of suicide substance-misusing and probably depressed, with a family history of depression and 
substance misuse - should help target suicide prevention more precisely. The knowledge that drug use and drug dependence significantly contribute to the psychological and social burdens that aggravate suicide risk needs to be better incorporated into overall suicide prevention strategies if the current upward trend in young suicide is to be reversed.

\section{ACKNOWLEDGEMENT}

J. N. is supported by a Wellcome Training Fellowship in Epidemiology.

\section{REFERENCES}

Allgulander, C., Allobeck, P., Przybeck, T. R., of al (1992) Risk of suicide by psychiatric diagnosis in Stockholm county. European Archives of Psychiatry and Clinical Neuroscience, 241. 323-326.

Breme, D. A., Perper, J. A., Mortiz, G., et ol (1993)

Psychiatric risk factors for adolescent suicide: a case control study. Journal of the American Academy of Child and Adolescent Psychiatry, 32, 521-529.

Caplehorn, J. R. M., Dalton, S.Y. N., Cluff, M. C., et ol (1994) Retention in methadone maintenance and heroin addicts' risk of death. Addiction, 89. 203-207.

Cartson, G. A., Rich, C. L., Grayson, P., et al (1991) Secular trends in psychiatric diagnosis of suicide victims. Journol of Affective Disorders, 21, 127-132.

Darke, S., Ross, J. \& Hall, W. (1996) Overdose among heroin users in Sydney, Australia: 2. Responses to overdose. Addiction, 91, 413-417.

JAN NEELEMAN, MRCPsych, Department of Social Psychiatry, University of Groningen: MICHAEL FARRELL, MRCPsych. Addiction Sciences Building. Windsor Walk, London SE5 9AF

Correspondence: Jan Neeleman, Department of Social Psychiatry, University of Groningen, PO Box 30.001,9700 RB Groningen. The Netherlands. Fax: +31503612082; e-mail: j.needleman@med.rug.nl

(First received 12 November 1996, final revision 24 March 1997, accepted 27 March 1997)

Department of Health (1996) Tockling Drugs Together: A Strategy for England, 1995-1998. London: HMSO

Deykin, E. Y. \& Buka, S. L. (1994) Suicidal ideation and attempts among chemically dependent adolescents. American Journal of Public Health, 84. 634-639.

Engström, A., Adamason, C., Allebeck, P., et al (1991) Mortality in patients with substance abuse; a follow up in Stockholm county. International journal of the Addictions. 26. $91-106$

Farrell, M., Neeleman, J., Gossop, M., et ol (1996) A Review of the Legislation. Regulation and Delivery of Methadone in 12 Member States of the European Union. Luxembourg: Office for Official Publications of the European Communities.

Fowler, R. C., Rich, C. L. \& Young, D. (1986) San Diego Suicide Study. 2 Substance Abuse in Young Cases. Archives of General Psychiatry. 43. 962-965.

Frischer, M., Bloor, M., Goldberg, D., et al (1993) Mortality among injecting drug users: a critical reappraisal. Journol of Epidemiology and Community Health, 47. 59-63.

Garrison, C. Z., McKoown, R. E., Valois, R. F., et ol (1993) Aggression, substance use and suicidal behaviours in high school students. American journal of Public Health, 83. 179-184.

Gunnell, D. Frankel, S. (1994) Prevention of suicide: aspirations and evidence. British Medical Journol, 308. 1227-1233
Hall, W. \& Farrell, M. (1997) Comorbidity of mental disorders with substance misuse. British journal of Psychiatry. 171. 4-5

Hawton, K., Fagg, J., Platt, S., et al (1993) Factors associated with suicide after parasuicide in young people. British Medical Journal, 306, 1641-1644.

Meltzer, H., Gill, B., Pettigrew, M., et al (1995) OPCS Survey of Psychiatric Morbidity in Great Britain. Report 1: The Prevalence of Psychiotric Morbidity among Adults Living in Private Households. London: OPCS.

Noeleman, J. 2 Wessely, S. (19970) Changes in classification of suicide in England and Wales: time trends and associations with coroners' professional backgrounds. Psychological Medicine. 27, 467-472.

_ _ (1997b) Drugs taken in fatal and non-fatal selfpoisoning: a study in South London. Acto Psychiatrica Scandinavica, 95, 283-287.

Rossow, I. (1994) Suicide among drug addicts in Norway. Addiction, 89, 1667-1673.

- (1996) Alcohol and suicide - beyond the link at the individual level. Addiction. 91. 1413-1416.

Shaffer, D., Gould, M. S., Fisher, P., et al (1996) Psychiatric diagnosis in child and adolescent suicide. Archives of General Psychiotry, 53. 339-348. 